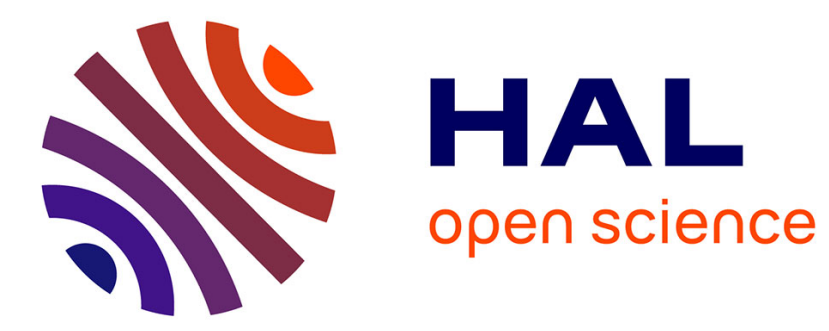

\title{
Biphasic mini-reactor for characterization of biocatalyst performance
}

\author{
Anne van den Wittenboer, Thomas Schmidt, Pia Müller, Marion Bettina \\ Ansorge-Schumacher, Lasse Greiner
}

\section{To cite this version:}

Anne van den Wittenboer, Thomas Schmidt, Pia Müller, Marion Bettina Ansorge-Schumacher, Lasse Greiner. Biphasic mini-reactor for characterization of biocatalyst performance. Biotechnology Journal, 2009, 4 (1), pp.44-n/a. 10.1002/biot.200800271 . hal-00477775

\section{HAL Id: hal-00477775 \\ https://hal.science/hal-00477775}

Submitted on 30 Apr 2010

HAL is a multi-disciplinary open access archive for the deposit and dissemination of scientific research documents, whether they are published or not. The documents may come from teaching and research institutions in France or abroad, or from public or private research centers.
L'archive ouverte pluridisciplinaire HAL, est destinée au dépôt et à la diffusion de documents scientifiques de niveau recherche, publiés ou non, émanant des établissements d'enseignement et de recherche français ou étrangers, des laboratoires publics ou privés. 


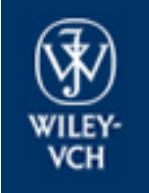

Biotechnology Journal

\section{Biphasic mini-reactor for characterization of biocatalyst} performance

\begin{tabular}{|r|l|}
\hline Journal: & Biotechnology Journal \\
\hline Manuscript ID: & BIOT-2008-0271.R2 \\
\hline Wiley - Manuscript type: & Technical Report \\
\hline Date Submitted by the \\
Author: & 03-Dec-2008 \\
\hline Complete List of Authors: & $\begin{array}{l}\text { van den Wittenboer, Anne; RWTH Aachen University, Department } \\
\text { of Biotechnology } \\
\text { Schmidt, Thomas; RWTH Aachen University, Department of } \\
\text { Biotechnology } \\
\text { Müller, Pia; RWTH Aachen University, Institut für Technische und } \\
\text { Makromolekulare Chemie } \\
\text { Ansorge-Schumacher, Marion; TU Berlin, Institute of Chemistry, } \\
\text { Enzyme Technology } \\
\text { Greiner, Lasse; RWTH Aachen University, Institut für Technische } \\
\text { und Makromolekulare Chemie }\end{array}$ \\
\hline Keywords: & \begin{tabular}{l} 
biocatalysis, biphasic media, mini-reactor \\
\hline
\end{tabular} \\
\hline
\end{tabular}

\section{s scholaroNE \\ Manuscript Central}




\title{
Technical Report ((3489 words))
}

\section{Biphasic mini-reactor for characterization of biocatalyst performance}

\author{
Anne van den Wittenboer ${ }^{1}$, Thomas Schmidt ${ }^{1}$, Pia Müller ${ }^{2}$, Marion B. Ansorge- \\ Schumacher $^{3}$ and Lasse Greiner ${ }^{2 *}$ \\ ${ }^{1}$ Department of Biotechnology, RWTH Aachen University, Aachen, Germany \\ 2 Institut für Technische und Makromolekulare Chemie, RWTH Aachen \\ University, Aachen, Germany \\ ${ }^{3}$ Institute of Chemistry, Enzyme Technology, TU Berlin, Berlin, Germany \\ * Corresponding author
}

Keywords: biocatalysis; biphasic media; mini-reactor

Correspondance: Dr. Lasse Greiner, Institut für Technische und

Makromolekulare Chemie, RWTH Aachen University, Worringerweg 1, 52074

Aachen, Germany

Email: greiner@itmc.rwth-aachen.de

Phone: +49-241-8026484 ; Fax: +49-241-8022177

\section{List of abbreviations:}

BAL, benzaldehyde lyase; CPCR, Candida parapsilosis carbonyl reductase; DMBA, 3,5-dimethoxy benzaldehyde; LbADH, Lactobacillus brevis alcohol dehydrogenase; MTBE, methyl-tert.-butyl ether; NADH, nicotinamide adenine dinucleotide; NADPH, nicotinamide adenine dinucleotide phosphate; ThDP, thiamine diphosphate; TMB, 3,3',5,5'-tetramethoxy benzoin 


\begin{abstract}
Biphasic reaction media are extending the scope of technical biocatalysis. Thorough investigation of the factors affecting catalyst performance under these conditions is of key importance for the successful implementation of catalytic processes. Here, we present a reactor setup suitable for comprehensive systematic characterization and optimization of biocatalyzed reactions in biphasic systems with distinct phases. It is distinguished by small volumes allowing reproducible experimentation with minimum amounts of solvent and catalyst. The interfacial area is kept constant and independent stirring of both phases is allowed in order to minimize superimposing effects. Evaporation of low-volatile organic solvents is prevented by use of airtight construction. The broad applicability of this minireactor is demonstrated with regard to determination of mass transfer, enzyme productivity, and enzyme stability in both batch and continuous mode.
\end{abstract}




\section{Introduction}

Application of biphasic reaction systems broadens the scope of biocatalytic transformations as compounds with low solubility or stability in water can be transformed. In these systems, the biocatalyst is usually located in the aqueous phase or at the interface between water and solvent, and the organic phase is the non-reactive phase acting as a reservoir [1, 2]. Most biocatalysts perform differently in biphasic reaction media than in purely aqueous or organic phases. This can be a result of changes in the concentration of substrates and products [36] in the vicinity of the catalyst, direct interactions of small amounts of dissolved solvent with the catalyst [7], or interaction of the catalyst with the interface between aqueous and organic phase [7-10]. These parameters can either affect activity/productivity or selectivity of the biocatalyzed reaction [3-9] or influence the stability of the catalyst $[6,10]$. The activity of many lipases, for instance, is considerably enhanced at interfaces whereas the same interaction may deactivate other enzymes [6, 10]. The particular impact of a biphasic system on a biocatalyzed reaction depends on the applied biocatalyst and the non-reactive solvent. For (bio-)technical application a thorough characterization of the biocatalysts' performances in biphasic systems under relevant conditions is essential. So far, only few studies deal with the investigation of enzymatic performance in aqueous-organic two-phase systems with two defined liquid phases. Often, immobilized catalysts are employed as an aqueous phase suspended in organic solvents [11]. Emulsions can also be used beneficially [e.g. 12, 13] but evaluation of mass transfer, concentration changes/ profiles and 
interactions between biocatalyst and solvent phase is sometimes difficult to accomplish since the interfacial area which is depending on droplet size and their lifetime is hardly accessible. Emulsion systems are therefore not applicable for a thorough characterization of biphasic systems, in contrast to studies that used systems with two defined and distinguishable liquid phases. Most examples are concerned with the interactions between biocatalyst and solvent phase, either revealing inactivation at the interface $[6,10]$ or contrariwise interfacial activity $[8,9]$.

Here, we present an advanced, all-purpose reactor set-up for a systematic labscale evaluation and optimization of biocatalyzed reactions in discrete biphasic systems. It is characterized by small volumes, a distinct and stable interfacial area between phases, and independent mixing of both phases. Exemplary applications to the investigation of mass transfer, enzyme activity, and solvent influences under process conditions are described and evaluated.

\section{Materials and methods}

\section{Chemicals and enzymes}

Enantiomerically pure 3,3',5,5'-tetramethoxy benzoin (TMB) was synthesized enzymatically with benzaldehyde lyase (BAL) according to [14]. 3,5-dimethoxy benzaldehyde (DMBA) was purchased from Alfa Aesar (Karlsruhe, Germany), $\mathrm{NADH}$ and $\mathrm{NADP}^{+}$were from Jülich Chiral Solutions (Jülich, Germany). All other solvents and reagents were from Sigma-Aldrich (Steinheim, Germany) of 
highest available purity and used without further purification. BAL was expressed and purified using the recombinant $E$. coli SG13009 $_{\text {prep4 }}$ [pBAL-his 6 ] according to [15]. Expression and purification of Candida parapsilosis carbonyl reductase (CPCR) was performed according to [16] by using the recombinant E. coli BL21(DE3) [pET26b(+)CPCR-his 6 ]. Lactobacillus brevis alcohol dehydrogenase (LbADH) was a gift from X-zyme (Düsseldorf, Germany).

\section{Reactor components}

The double jacket glass vessel and the reactor head were built by the university workshop. The outer case of the head and the upper phase stirrer were made from stainless steel, all other parts were made from poly(ether ether ketone) (PEEK). All fittings and tubes were also made from PEEK and were purchased from Upchurch Scientific (Oak Habor, USA). For continuous dosage membrane pumps BF414S32 (Telab, Langenfeld, Germany) and syringe pumps MDSP3f (Micromechatronic Technologies MMT, Siegen, Germany), for batch experiments Liquiport NF100TT.185 membrane pumps (KNF, Freiburg, Germany) were used. Temperature was controlled using a water bath (Thermo Haake, Karlsruhe, Germany) or a cryostat (Huber, Germany). Magnetic stirrers for the lower phase were from IKA (Staufen, Germany). Miniaturized magnetic stirrers (Variomag, Daytona Beach, USA) were used for the upper phase.

\section{Batch experiments with BAL}

Experiments were followed inline by UV-Vis spectrometry in both n-hexane and the aqueous phase (potassium phosphate buffer and $25 \% \mathrm{DMF}, \mathrm{pH} 8.5$ ). UV-Vis 
spectrometry was performed using a Varian Cary 50 (Varian, USA) equipped with two flow-through UV-Quartz cuvettes (Hellma, Germany) with a path length of $5.0 \mathrm{~mm}$. Measurement of substrate and product was performed at $325 \mathrm{~nm}\left(\varepsilon_{\mathrm{DMBA}}\right.$ : $2.434 \mathrm{mM}^{-1} \mathrm{~cm}^{-1}$ (buffer), $2.419 \mathrm{mM}^{-1} \mathrm{~cm}^{-1}$ (n-hexane); $\varepsilon_{\mathrm{TMB}}: 2.26 \mathrm{mM}^{-1} \mathrm{~cm}^{-1}$ (buffer), $2.585 \mathrm{mM}^{-1} \mathrm{~cm}^{-1}$ (n-hexane)) or in intervals of 0.5 minutes wavelength scans $(250-350 \mathrm{~nm})$ were taken of both phases and concentrations of all reactants were calculated according to Lambert-Beer's law with extinction coefficients determined by independent samples (data not shown).

\section{Continuous experiments with LbADH}

Typically for continuous reaction, a $5.0 \mathrm{~mL}$ aqueous reactive phase contained 1.0 $\mathrm{mg} \mathrm{mL} \mathrm{m}^{-1}$ unpurified $\mathrm{LbADH}$ and $0.10 \mathrm{mM} \mathrm{NADP}$. Reaction was started by enzyme addition. Online GC-analysis of LbADH samples was performed using a 6890 GC (Agilent, Germany) equipped with a CP-Chirasil-Dex CB capillary column (Varian, Germany) isothermally at $40^{\circ} \mathrm{C}\left(\mathrm{H}_{2}, 1.0\right.$ bar, injector $300^{\circ} \mathrm{C}$, detector $280^{\circ} \mathrm{C}$ ). Typical retention times: butanone $5.6 \mathrm{~min} ;(R)$-butanol $6.8 \mathrm{~min}$; (S)-butanol 7.1 min; 1-butanol $12.2 \mathrm{~min}$ as standard.

\section{Continuous experiments with CPCR}

$\mathrm{CPCR}$ and $\mathrm{NADH}$ were provided in $5 \mathrm{~mL}$ aqueous phase overlaid with $5 \mathrm{~mL}$ of organic phase. Organic phase was continuously added by a dosing pump and removed by an overflow mechanism (pressurized with solvent-saturated nitrogen). Residence times were controlled by the volumetric flow rate of the organic phase. Samples from the outflow were analyzed via GC on a HP5890 Series II (Agilent, 
Germany) equipped with a FS-Supreme 5 capillary column (CSChromatographie, Langerwehe, Germany). Dodecane (20 $\mathrm{mM})$ was used as internal standard in the organic phase. Typical retention times: 1-phenylethanol $8.1 \mathrm{~min}$; acetophenone $8.5 \mathrm{~min}$; dodecane $11.1 \mathrm{~min}\left(\mathrm{~N}_{2} 0.35\right.$ bar, injector $200^{\circ} \mathrm{C}$, detector $\left.290^{\circ} \mathrm{C}, 80^{\circ} \mathrm{C}, 98^{\circ} \mathrm{C}(2 \mathrm{~K} / \mathrm{min}), 200^{\circ} \mathrm{C}\left(35^{\circ} \mathrm{C} / \mathrm{min}\right)\right)$.

\section{Results and discussion}

For the experimental determination of non-miscible solvent combinations on catalysts a suitable setup should combine and extend a number of advantageous features of previously reported designs $[8,9,10,17]$. It should allow reproducible experimentation with minimum amounts to enable early testing and screening of (bio-)catalysts under biphasic conditions. The interfacial area should be constant and the setup should allow the independent stirring of both phases to minimize superimposing effects. For the use with low-volatile organic solvents airtight construction was required to prevent evaporation. The number of materials should be kept to a minimum and allow operation with a wide range of solvents.

The lab-scale reactor designed in this study is constructed of glass to allow visual inspection. The reaction room is a cylindrical glass vessel equipped with a tightly fitting head piece for inlet and outlet ports as well as the overhead suspension for stirring of the upper phase (Figure 1). By means of a double jacket temperature control is achieved. The interfacial area between overlaid immiscible solvents has a dimension of $3.1 \mathrm{~cm}^{2}$ and is kept stable by independent, counter current stirring 
of both phases using magnetic stir bars. For the lower phase standard equipment is applied. The upper phase stirring shaft is driven by a magnet in the head piece. The reaction vessel has a volume of $10 \mathrm{~mL}$ typically used for volume ratios of one. Volume ratios of up to three or one third $(7.5: 2.5 \mathrm{v}: \mathrm{v})$, respectively, can also be used (data not shown). Five ports with 1/4-28 threads for flangeless airtight connections are provided for flexibility in operational mode and sampling. Wetted materials are glass, stainless steel and PEEK or PTFE tubing for sampling. We applied the cell in a range of examples from our current research. This includes the use in both batch and continuous mode.

The enantioselective $\mathrm{C}-\mathrm{C}$ coupling of aldehydes by thiamine diphosphate dependent enzymes is of high current interest for the synthesis of enantiomerically enriched hydroxy ketones [18]. The applicability of this reaction can be broadened considerably by the utilisation of biphasic conditions as substrates and in particular the products are generally poorly soluble in water. The coupling of 3,5dimethoxy benzaldehyde (DMBA) to 3,3',5,5'-tetramethoxy benzoin (TMB) by benzaldehyde lyase from Pseudomonas fluorescens (BAL) in the biphasic system of hexane and aqueous potassium phosphate buffer with $25 \%$ DMF (v/v) is investigated as model system (Figure 2A).

One of the key parameters influencing the performance of biocatalyzed reactions in biphasic systems is the transfer of reactants between the phases. The apparent rate is heavily governed by mass transfer and thermodynamic boundaries. Consequently, determination of mass transfer is required for both understanding and optimization of biphasic catalytic systems. Aqueous and organic phase were 
connected to flow-through cuvettes in an UV-Vis spectrometer, allowing a timedependent inline-analysis of DMBA and TMB concentrations in both phases with a high data density. The total volume of each phase was $9 \mathrm{~mL}$ as increased by the volume in tubings and both phases were presaturated with the respective other in order to avoid changes in phase ratio.

Based on the resulting curves, mass transfer coefficients of $(9.96 \pm 0.05) \cdot 10^{-5}$ $\mathrm{dm} \cdot \mathrm{s}^{-1}$ and $(5.74 \pm 0.15) \cdot 10^{-5} \mathrm{dm} \cdot \mathrm{s}^{-1}$ were determined for DMBA and TMB, respectively, according to the method of Peters and Zavrel [19] (Figure 2B). Additionally, equilibrium partition coefficients $\left(K_{i}=c_{i, \text { org }} / c_{i, a q}\right)$ of $3.434 \pm 0.039$ (DMBA) and $0.370 \pm 0.011(\mathrm{TMB})$ can be derived. The small standard deviations of maximum $3 \%$ indicate good reproducibility.

The same setup was applied to the reactive system with BAL in the aqueous phase. A typical time course for a batch experiment is shown in Figure 2C. In combination with the mass transfer measurements shown above it can be concluded that the re-extraction of the product TMB into the non-reactive phase is rate limiting.

In order to demonstrate the applicability of the two phase cell for continuous reactions the setup was varied to allow continuous dosage and withdrawal of the non-reactive phase. As a model reaction ketone reduction catalyzed by two different reductases, namely Lactobacillus brevis alcohol dehydrogenase and Candida parapsilosis carbonyl reductase, was investigated, both with substrate dependent cofactor regeneration (Figure 3A). 
For LbADH reactions a syringe pump fed the substrates butanone and 2-propanol in MTBE into the reactor. The reservoir phase was withdrawn by another pump and fed to the GC flow cell. At intermittent time intervals, samples from the GC flow cell and external standard 1-butanol where withdrawn automatically and injected for analysis. A typical time course of the reaction with conversion and enantiomeric excess $(e e)$ is shown in Figure 3B. After an initial lag phase of 2 hours which is caused by the dead volume in the peripherals such as pump and tubing the reaction reaches a steady state of $70 \%$ conversion after 8 hours (4 residence times). The $e e$ in the steady state is at $91 \%$ which is a very good result for the comparably difficult substrate $R$-2-butanone. Furthermore, the absence of apparent deactivation is remarkable and target of current investigations.

A major task when setting up a biphasic reaction is the selection of a suitable solvent. Apart from characteristics as price, bio-degradability and toxicity, which are rather easy to evaluate, the ability to solve substrates and products and the impact on the catalyst itself are the most important features. Solubility of reactants as well as their partition in different two-phase systems can be predicted quite precisely by means of various parameters and the respective methods $[3,19,20]$. In contrast, the effects on the biocatalyst are still barely predictable, although many studies tried to correlate the performance of biocatalysts with various physicochemical parameters such as dielectric constants, $\log \mathrm{P}$ or the surface tension [21]. Thus, it is still necessary to screen potential solvents experimentally to find the most suitable. Often storage stability of biocatalyst in presence of different solvents is measured in order to select a solvent [e.g. 7, 22, 23], but the 
more significant operational stability is rarely investigated. With the here introduced set-up it is rather easy to screen a set of potential solvents that ensure good solubility and partition for their biocompatibility for a target biocatalyst under reaction conditions. For the CPCR-catalyzed reduction of acetophenone to 1-phenylethanol different organic solvents were tested as organic phase in continuous mode in order to evaluate their impact on enzyme stability under reaction conditions.

The impact of different solvents can be clarified in the reaction setup as is examplified by the continuous reactions with cyclohexane and heptane as nonreactive phase (Figure 3C). Apart from the solvent used, all other parameters were kept constant, but it can clearly be seen, that the solvents have different effects on the enzyme's performance. The decrease of conversion is a measure of enzyme deactivation and the slope of this decrease is proportional to the deactivation rate if mass transfer is fast compared to the reaction rate. For the example a 4-fold increased deactivation was found when the non-reactive solvent was changed from heptane $\left(0.039 \mathrm{~h}^{-1} \pm 0.002\right)$ to cyclohexane $\left(0.172 \mathrm{~h}^{-1} \pm 0.002\right)$.

\section{Concluding remarks}

The presented reactor is an advanced and modular tool for the study of biphasic catalytic reactions. It can be employed as the core piece in both continuous and batchwise operated investigations. Sampling of minimum amounts from the reactor is possible without disturbance. The direct connectivity to both 
spectrometry and chromatographic equipment facilitates high data density. The minimum scale allows the investigation with minimal consumption of catalyst, substrate and solvent allowing early on testing of relevant biphasic reaction conditions during process development.

The examples demonstrate the applicability and modularity of the reactor setup and highlight already the importance of the assessment of these influences for both the BAL catalyzed enantioselective C-C coupling as well as the enantioselective reduction of ketones by $\mathrm{LbADH}$ and CPCR. Furthermore, the results for the determination of mass transfer rates and equilibrium partition coefficients demonstrate the applicability for non reactive measurements with high accuracy. 


\section{Acknowledgements}

The work was funded by the Deutsche Forschungsgemeinschaft (Bonn, Germany) within GRK 1166 "Biocatalysis in non-conventional media", SFB 540 "Modelbased experimental analysis of kinetic phenomena in fluid multi-phase reactive systems" and AiF (KF0174001UL5). We thank Prof. (em.) Dr. M.-R. Kula (Institute for Enzyme Technology, University of Düsseldorf) for provision of BAL-expression vector “pBAL-His,", Dr. S. Na'amnieh (X-Zyme, Düsseldorf, Germany) for the kind gift of LbADH, and Dr. S. K. Karmee, R. Sojka, P. Hochstenbach as well as H. Kronenberg (all RWTH Aachen University) for technical assistance and discussion.

The authors have declared no conflict of interest. 


\section{References}

[1] Fernandes, P., Cabral, J. M. S., Biocatalysis in biphasic systems: general, in: Carrea, G., Riva, S. (Eds.), Organic synthesis with enzymes in non-aqueous media, Wiley-VCH Verlag, Weinheim 2008, pp. 191-210.

[2] Eckstein, M. F., Peters, M., Lembrecht, J., Spiess, A. C. et al., Maximise equilibrium conversion in biphasic catalysed reactions: mathematical description and practical guideline. Adv. Synth. Catal. 2006, 348, 1591-1596.

[3] Halling, P., Solvent selection for biocatalysis in mainly organic systems: predictions of effects on equilibrium position. Biotechnol. Bioeng. 1990, 35, 691701.

[4] Spiess, A., Eberhard, W., Peters, M., Eckstein, M. et al., Prediction of partition coefficients using COSMO-RS: solvent screening for maximum conversion in biocatalytic two-phase reaction systems. Chem. Eng. Process 2008, 47, 10341041.

[5] Baldascini, H., Ganzeveld, K., Janssen, D., Beenackers, A., Effect of mass transfer limitations on the enzymatic kinetic resolution of epoxides in a twoliquid-phase system. Biotechnol. Bioeng. 2001, 73, 44-54.

[6] Gerrits, P., Willemann, W., Straathof, A., Heijnen, J. et al., Mass transfer limitation as a tool to enhance the enantiomeric excess in the enzymatic synthesis of chiral cyanohydrins. J. Mol. Catal., B Enzym. 2001, 15, 111-121.

[7] Ghatorae, A., Guerra, M., Bell, G., Halling, P., Immiscible organic solvent inactivation of urease, chymotrypsin, lipase, and ribonuclease: separation of 
dissolved solvent and interfacial effects. Biotechnol. Bioeng. 1994, 44, 13551361.

[8] Hickel, A., Radke, C., Blanch, H., Hydroxynitrile lyase at the diisopropyl ether/ water interface: evidence for interfacial enzyme activity. Biotechnol. Bioeng. 1999, 65, 425-436.

[9] Hickel, A., Radke, C., Blanch, H., Role of organic solvents on the Pahydroxynitrile lyase interfacial activity and stability. Biotechnol. Bioeng. 2001, $74,18-28$.

[10] Baldascini, H., Janssen, D., Interfacial inactivation of epoxide hydrolase in two-liquid-phase systems. Enzyme Microb. Technol. 2005, 36, 285-293.

[11] Ansorge-Schumacher, M. B., Two-phase systems with solidified water phases - tools for technical use of sensitive catalysts. Mini Rev. Org. Chem. 2007, $4,243-245$.

[12] Willemann, W. F., Neuhofer, R., Wirth, I., Pöchlauer, P. et al., Development of $(R)$-4-hydroxymandelonitrile synthesis in an aqueous-organic biphasic stirred tank batch reactor. Biotechnol. Bioeng. 2002, 79, 154-164.

[13] Sandford, V., Breuer, M., Hauer, B., Rogers, P. et al., $(R)$ phenylacetylcarbinol production in aqueous/organic two-phase systems using partially purified pyruvate decarboxylase from Candida utilis. Biotechnol. Bioeng. 2005, 91, 190-198. 
[14] Schmidt, T., Experimentelle Analyse, Modellierung und biochemische Charakterisierung von Ein-und Zweiphasensystemen für die technische Biokatalyse. Dissertation RWTH Aachen University, Aachen, 2008.

[15] Janzen, E., Müller, M., Kolter-Jung, D., Kneen M. M. et al., Characterization of benzaldehyde lyase from Pseudomonas fluorescens: A versatile enzyme for asymmetric C-C bond formation. Bioorg. Chem. 2006, 34, 345-361.

[16] Bhattacharjee, M., Cloning, expression, characterization and immobilization of carbonyl reductase from Candida parapsilosis. Dissertation RWTH Aachen University, Aachen, 2005.

[17] Woodley, J., Brazier, A. Lilly, M., Lewis cell studies to determine reactor design data for two-liquid-phase bacterial and enzymic reactions. Biotechnol. Bioeng. 1991, 37, 133-140.

[18] Demir, A. S., Sesenoglu, O., Eren, E., Hosrik, B. et al., Enantioselective synthesis of alpha-hydroxy ketones via benzaldehyde lyase-catalyzed C-C bond formation reaction. Adv. Synth. Catal. 2002, 344, 96-103.

[19] Peters M., Zavrel, M., Kahlen, J., Schmidt, T. et al., Systematic approach to solvent selection for biphasic systems with a combination of COSMO-RS and a dynamic modelling tool. Eng. Life Sci. 2008, in press.

[20] Peters, M., Greiner, L., Leonhard, K. Illustrating computational solvent screening: Prediction of standard Gibbs energies of reaction in solution, AIChE J 2008, 54, 2729-2734. 
[21] Filho, M. V., Stillger, T., Müller, M., Liese, A., et al., Is $\log P$ a convenient criterion to guide the choice of solvents for biphasic enzymatic reactions? Chem. Int. Ed. 2003, 42, 2993-2996.

[22] Gröger, H., Hummel, W., Buchholz, S., Drauz, K., et al., Practical asymmetric enzymatic reduction through discovery of a dehydrogenasecompatible biphasic media. OrgLetters 2002, 5, 173-176.

[23] Bauer, M., Griengl, H., Steiner, W., Parameters influencing stability and activity of a $S$-hydroxynitrile lyase from Hevea brasiliensis in two-phase systems. Enzyme Microb. Technol. 1999, 24, 514-522. 
Figure 1. Basic setup of the biphasic lab-scale reactor (dimensions in $\mathrm{mm}$ ).

Figure 2. A Benzoin condensation with benzaldehyde lyase (BAL). B Timedependent DMBA and TMB concentration profiles in buffer (decreasing curves) and n-hexane (increasing curves) derived from spectrophotometry in the absence of BAL (initial concentrations: $5 \mathrm{mM}$ (DMBA) and $2.5 \mathrm{mM}$ (TMB) in potassium phosphate buffer/DMF; dotted lines: measured data; solid lines: calculated expected values [19]). C BAL-catalyzed condensation of DMBA to TMB in a two-phase system consisting of buffer and n-hexane (aqueous phase: $1 \mu \mathrm{g} \mathrm{mL}^{-1}$ BAL, $0.25 \mathrm{mM}$ ThDP, $0.25 \mathrm{mM} \mathrm{MgSO}$, 5 mM DMBA; black lines: DMBA; grey lines: TMB; solid lines: organic phase; dashed lines: aqueous phase).

Figure 3. A Ketone reduction catalyzed by LbADH (substrate butanone) and CPCR (substrate acetophenone) with substrate dependent cofactor regeneration. B Conversion and enantiomeric excess (ee) as a function of time for the continuous reduction of butanone with $\mathrm{LbADH}\left(50 \mathrm{mmol} \mathrm{L}^{-1}\right.$ butanone and 2.0

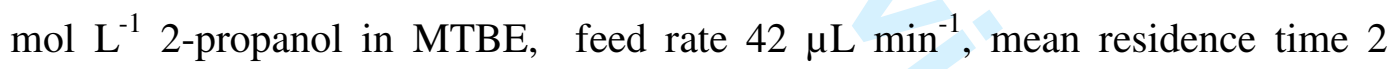
hours). C Acetophenone reduction catalyzed by CPCR with cyclohexane and heptane as organic phase (aqueous phase: $0.1 \mathrm{M}$ triethanolamine buffer $\mathrm{pH}$ 8.0, 10 $\mu \mathrm{g} \mathrm{mL}^{-1} \mathrm{CPCR}, 10 \%(\mathrm{v} / \mathrm{v})$ isopropanol, $1 \mathrm{mM} \mathrm{NADH}$; organic phase: $100 \mathrm{mM}$ acetophenone, $20 \mathrm{mM}$ dodecane in respective solvent; mean residence time 1.8 hours). 

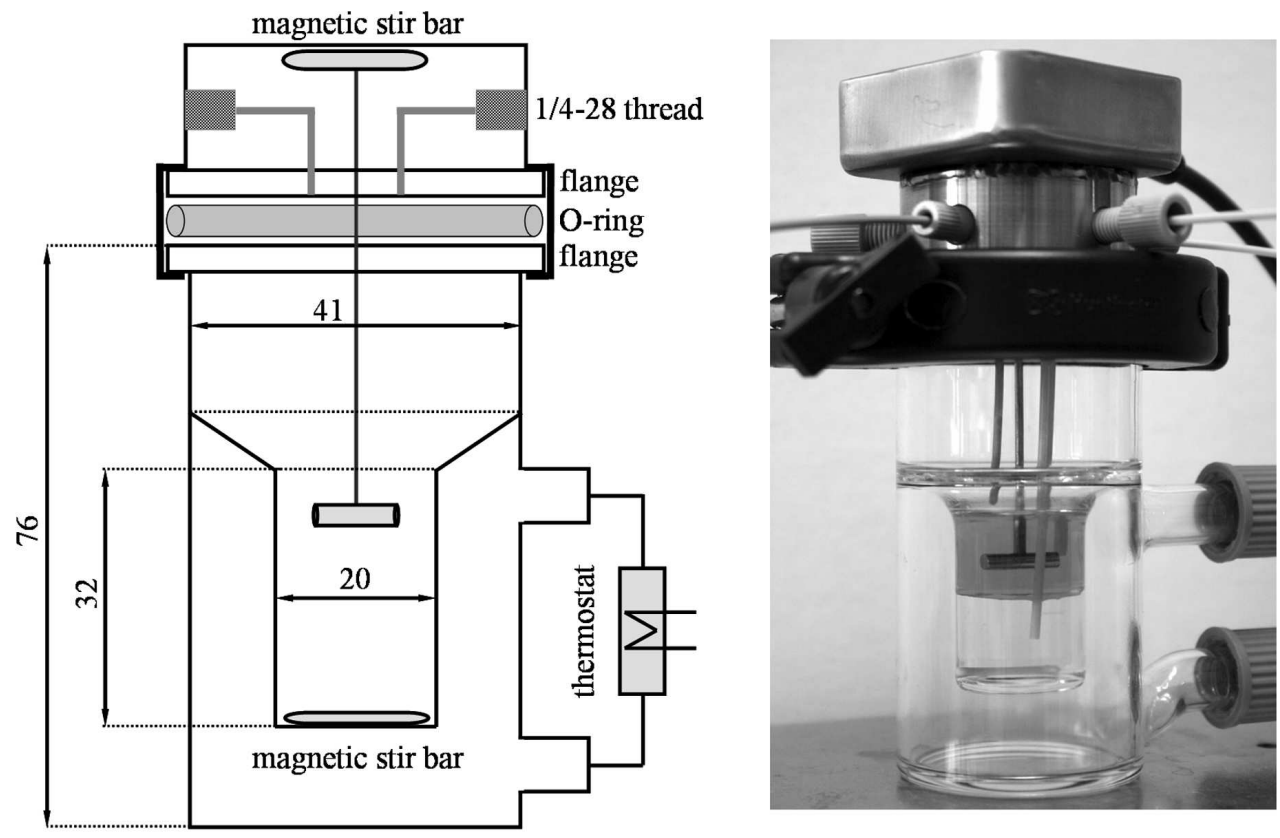

Figure 1. Basic setup of the biphasic lab-scale reactor (dimensions in $\mathrm{mm}$ ). $120 \times 80 \mathrm{~mm}(400 \times 400$ DPI $)$ 
Figure 2. A Benzoin condensation with benzaldehyde lyase (BAL). B Time-dependent DMBA and TMB concentration profiles in buffer (decreasing curves) and n-hexane (increasing curves) derived from spectrophotometry in the absence of BAL (initial concentrations: $5 \mathrm{mM}$ (DMBA) and $2.5 \mathrm{mM}$ (TMB) in potassium phosphate buffer/DMF; dotted lines: measured data; solid lines: calculated expected values [19]). C BAL-catalyzed condensation of DMBA to TMB in a two-phase system consisting of buffer and $\mathrm{n}$-hexane (aqueous phase: $1 \mu \mathrm{g} \mathrm{mL}-1 \mathrm{BAL}, 0.25 \mathrm{mM}$ ThDP, $0.25 \mathrm{mM} \mathrm{MgSO} 4,5 \mathrm{mM}$ DMBA; black lines: DMBA; grey lines: TMB; solid lines: organic phase; dashed lines: aqueous phase). 


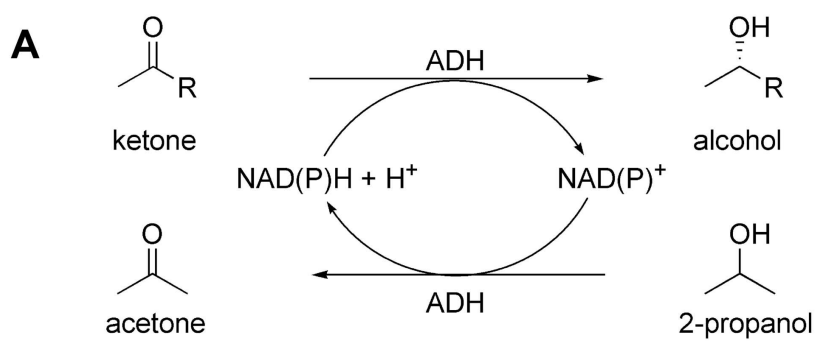

\section{B}

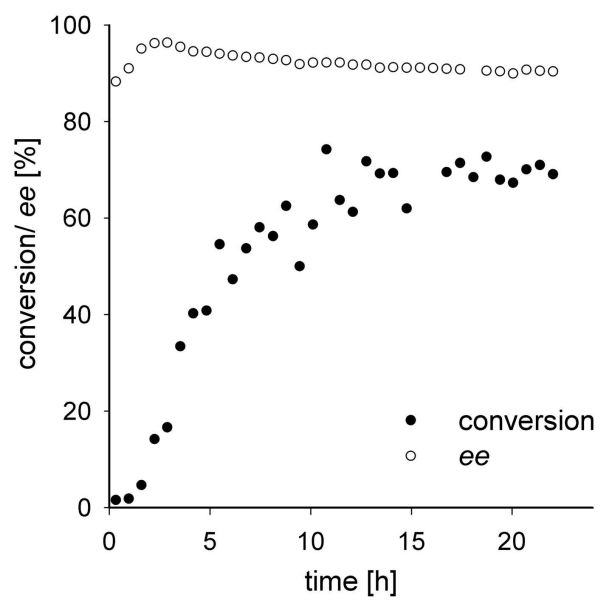

C

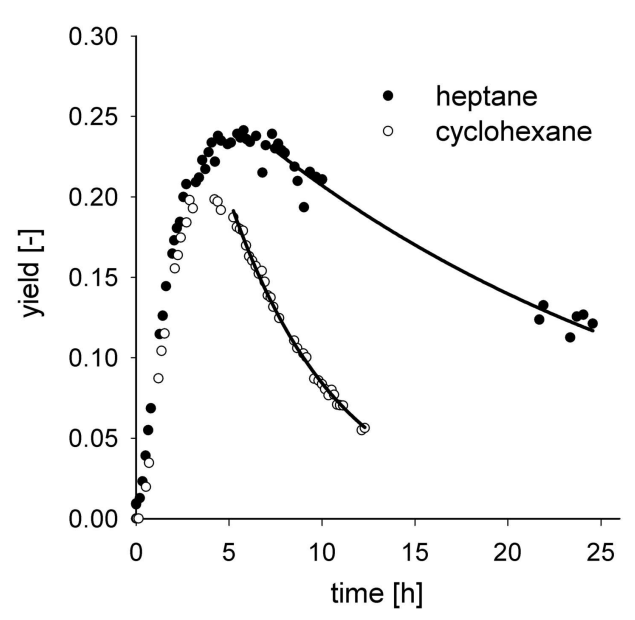

Figure 3. A Ketone reduction catalyzed by LbADH (substrate butanone) and CPCR (substrate acetophenone) with substrate dependent cofactor regeneration. B Conversion and enantiomeric excess (ee) as a function of time for the continuous reduction of butanone with LbADH $(50 \mathrm{mmol} \mathrm{L}-$ 1 butanone and $2.0 \mathrm{~mol} \mathrm{L-1}$ 2-propanol in MTBE, feed rate $42 \mu \mathrm{L}$ min-1, mean residence time 2 hours). C Acetophenone reduction catalyzed by CPCR with cyclohexane and heptane as organic phase (aqueous phase: $0.1 \mathrm{M}$ triethanolamine buffer $\mathrm{pH} 8.0,10 \mu \mathrm{g} \mathrm{mL}-1 \mathrm{CPCR}, 10 \%(\mathrm{v} / \mathrm{v})$ isopropanol, $1 \mathrm{mM} \mathrm{NADH}$; organic phase: $100 \mathrm{mM}$ acetophenone, $20 \mathrm{mM}$ dodecane in respective solvent; mean residence time 1.8 hours). $129 \times 104 \mathrm{~mm}(600 \times 600 \mathrm{DPI})$ 